
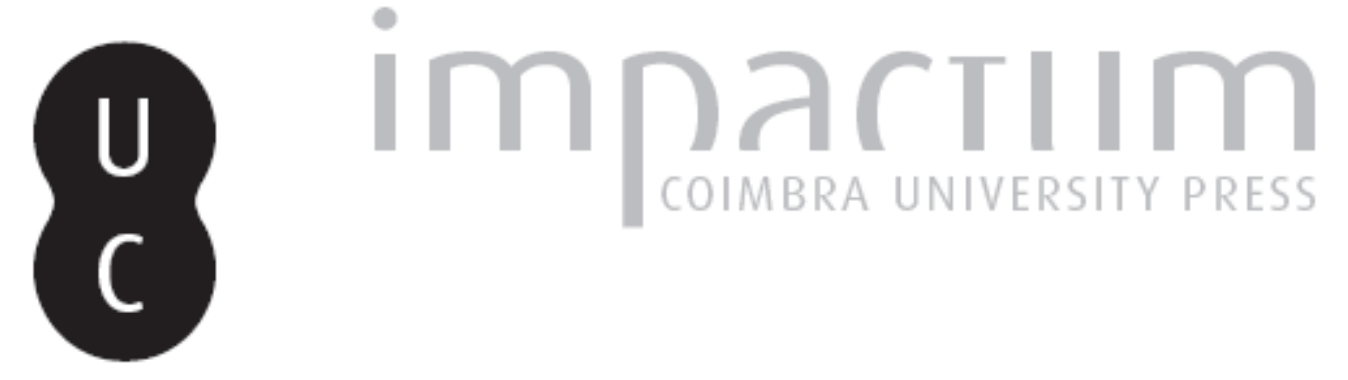

\title{
O castigo físico de crianças: estudo de revisão
}

Autor(es): $\quad$ Ribeiro, Cristina Silveira; Malta, Wilson; Magalhães, Teresa

Publicado por: Imprensa da Universidade de Coimbra

URL persistente:

URl:http://hdl.handle.net/10316.2/33216

DOI:

DOI:http://dx.doi.org/10.14195/1647-8630_22_3

Accessed : $\quad$ 26-Apr-2023 15:10:47

A navegação consulta e descarregamento dos títulos inseridos nas Bibliotecas Digitais UC Digitalis, UC Pombalina e UC Impactum, pressupõem a aceitação plena e sem reservas dos Termos e Condições de Uso destas Bibliotecas Digitais, disponíveis em https://digitalis.uc.pt/pt-pt/termos.

Conforme exposto nos referidos Termos e Condições de Uso, o descarregamento de títulos de acesso restrito requer uma licença válida de autorização devendo o utilizador aceder ao(s) documento(s) a partir de um endereço de IP da instituição detentora da supramencionada licença.

Ao utilizador é apenas permitido o descarregamento para uso pessoal, pelo que o emprego do(s) título(s) descarregado(s) para outro fim, designadamente comercial, carece de autorização do respetivo autor ou editor da obra.

Na medida em que todas as obras da UC Digitalis se encontram protegidas pelo Código do Direito de Autor e Direitos Conexos e demais legislação aplicável, toda a cópia, parcial ou total, deste documento, nos casos em que é legalmente admitida, deverá conter ou fazer-se acompanhar por este aviso.

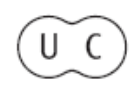




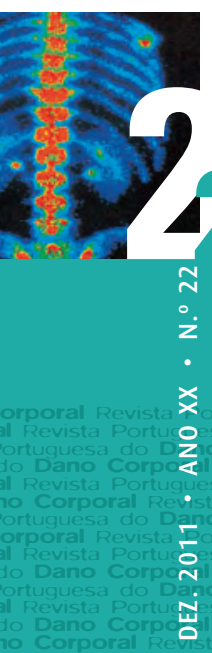

$$
\text { REVISTA PORT U/GUESA }
$$

do
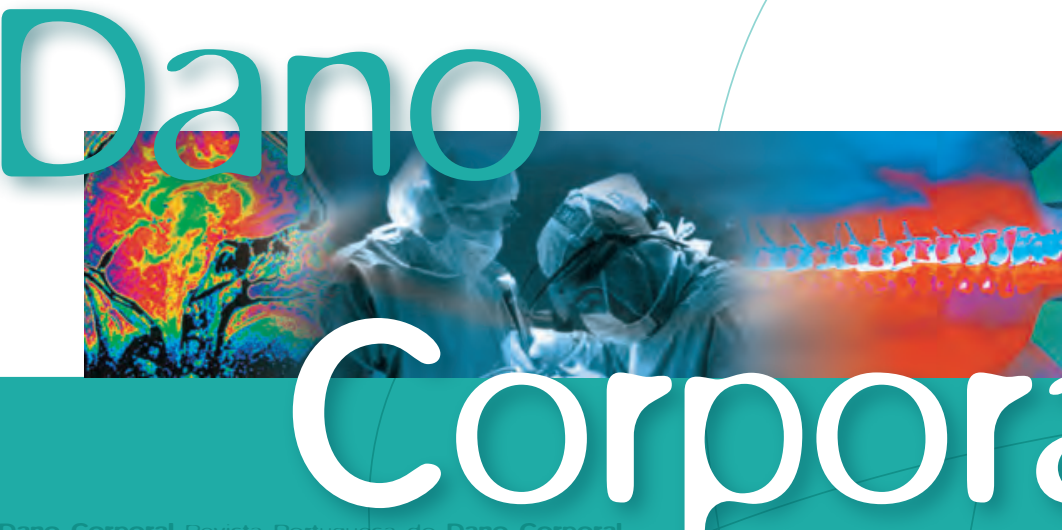

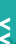

Oesa do Dano Corporal Revista Portuguesa do Dano Corporal

Zo Corporal Revista Portuguesa do Dano Corporal Revista Portuguesa do Dano Corporal

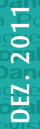

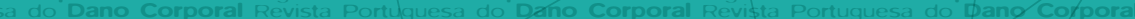

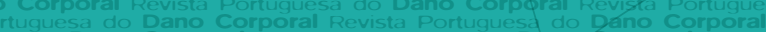

Revista Portuguesa do Dano Corporal Revista Rortuguesa do Dano Corporal
Ro Corporal Revista Portuguesa do Dano Corpgral Revista Portuguesa do Dano Corporal

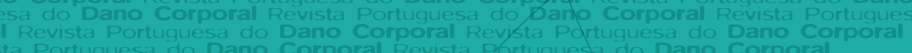




\section{0 castigo físico de crianças. Estudo de revisão}

Cristina Silveira Ribeiro ${ }^{(1,2,3)}$, Wilson Malta ${ }^{(4)}$, Teresa Magalhães ${ }^{(1-4)}$

\section{INTRODUÇÃO}

O castigo físico (CF) de crianças, tendo em vista a sua educação e correção, constitui um comportamento que tem sido socialmente legitimado ao longo da História da humanidade, o qual ou encontrava conforto na lei ou não estava criminalizado (como maioritariamente continua a não estar), tratando-se, por isso, de uma prática generalizada a nível mundial. Este comportamento, que num grande número de casos persiste, é pois estimulado por fatores cognitivos presentes nas crianças e seus cuidadores, e por crenças, muitas delas perpetuadas em dizeres populares, como: "De pequenino se torce o pepino", "Se não vais ao bem vais ao mal", "Quem bem ama bem castiga".

No entanto, na atualidade é outra a visão sobre estas práticas, quer em termos científicos e sociais, quer em termos de direitos humanos e legais, pelo menos em alguns países, começando-se a questionar a sua legitimidade ou, pelo menos, o limite em que elas não poderão ser toleradas por constituírem um abuso contra as crianças.

De facto, desde há largos anos que em vários países têm vindo a ser implementadas medidas educacionais, sociais e legais no sentido de limitar e reprimir o uso do $\mathrm{CF}$ em contexto educacional, chegando-se até à punição criminal desta conduta. Em 1996, o Third National Incidence Study (NIS-3) considerou pela primeira vez que o CF sobre crianças constituía uma forma de maus-tratos (Sedlak e col, 1996).

\footnotetext{
1 Faculdade de Medicina da Universidade do Porto

2 Instituto Nacional de Medicina Legal, I.P. - Delegação do Norte

3 CENCIFOR - Centro de Ciências Forenses, Portugal

4 Instituto de Ciências Biomédicas "Abel Salazar" da Universidade do Porto
} 
Atualmente, de acordo com a OMS e a UNICEF, o CF deve ser entendido como uma forma de abuso (WHO \& ISPCAN, 2006). Aliás, neste sentido vai também o atual Código Penal português, que nos crimes de "Violência doméstica" (artigo $152^{\circ}$ ) e de "Maus tratos" (artigo 152 -A) faz referência aos castigos corporais relacionados com os casos que acontecem na família ou estruturas equiparadas e com os que acontecem em contexto institucional ou de dever de cuidado, respetivamente.

Importa, pois, repensar o conceito de $\mathrm{CF}$, de uma forma objetiva e abrangente, designadamente no que aos seus limites concerne. Este passo será fundamental para se poder distinguir entre castigo físico e abuso (que inclui violência doméstica ou maus tratos, na perspetiva do Código Penal português), tanto mais que sabemos que a grande parte das denúncias de abuso infantil pelos cuidadores recaem hoje sobre casos em que a prática denunciada teria como objetivo, alegadamente, uma finalidade educativa, concretizada através do $\mathrm{CF}$.

Assim, tendo em vista promover a reflexão sobre o assunto, apresenta-se um estudo de revisão sobre a evolução das abordagens sociais, científicas, religiosas e legais do CF aplicado a crianças como forma de disciplina.

\section{DISCIPLINA E CASTIGO}

Apesar de usados por vezes de forma indiferenciada, disciplina e castigo constituem diferentes conceitos.

A disciplina é algo que se cultiva, estimula e deve impor, sendo fundamental para o harmonioso funcionamento das relações humanas numa família e sociedade. O termo disciplina reporta-nos a Durkheim (início do século XX) e Foucault (década de 60/70), cujos estudos, produzidos em tempos e contextos diversos, e alvos de diferentes significados, apresentam um caráter sempre atual, na medida em que abordam a questão da disciplina a partir da noção moral (Durkheim) e de normalização (Foucault) (Bourdieu, 1996) - " (...) Provavelmente nenhum outro sociólogo de educação terá, melhor do que Durkheim, posto em evidência a função do controlo social inerente à disciplina escolar, ao relacioná-la, simultaneamente, com a necessidade da educação moral e de ordem social". Durkheim (Durkheim, 1984) afirma que "a família constitui um ambiente que, pelo seu calor natural, se apresenta particularmente apto a fazer despontar as primeiras inclinações altruístas, os primeiros sentimentos de solidariedade, mas a moral que ali se pratica é sobretudo afetiva. É na escola que a criança deve adquirir o necessário respeito pela regra e aprender a cumprir o seu dever. Assim, a escola desempenha o 
importante papel de guarda avançada da moral e é através da escola que a coesão social é assegurada".

O castigo corresponde a uma prática (por ação ou omissão), que tem usualmente como objetivo promover a correção, punindo ou reprimindo a indisciplina ou uma conduta que se considera incorreta, no sentido de induzir uma mudança de atitude ou comportamento. Pode acontecer no âmbito de um sistema legal (e.g., a um trabalhador, a um delinquente, de acordo com um determinado normativo legal, seja ele disciplinar ou penal), a nível institucional (e.g., a uma criança na escola) ou no contexto familiar (e.g., a uma criança em casa) (Magalhães, 2010).

Os perfis destas condutas estão de acordo com a cultura da época e sociedade em que estas tenham lugar, podendo haver, ou não, restrições legais face às mesmas (Magalhães, 2010).

Genericamente podem classificar-se os castigos como: (a) Impositivos [sujeição da pessoa a algo de penoso ou oneroso/pecuniário (e.g., multa)]; (b) Restritivos [aquele que restringe a realização de uma determinada atividade por uma pessoa ou corporal (e.g., prender, suspender, impedir a pessoa de sair de casa, de sair da sala de aulas no intervalo, de ver televisão ou de jogar)] - destes, a maior parte têm caráter educativo e não põe em causa os direitos das pessoas; (c) Corporais ou físicos, constituindo uma forma violenta de repressão ou coação que se traduz na produção intencional de dor física a alguém (e.g., açoite, palmada, bofetada) (Magalhães, 2010) Esta última forma não constituirá o meio mais adequado para punir a indisciplina sendo, quase sempre, desproporcional face à "gravidade" daquela.

Recentemente é notória a global e crescente preocupação sobre a real prevalência dos CF no espaço família - perpetuado pela permissividade e até aprovação social deste gesto -, bem como pela melhor compreensão deste fenómeno, designadamente no que concerne às suas diferentes apresentações e limites. A maioria dos CF dirigidos a crianças envolve o uso da mão (e.g., bofetada, murros, puxão de cabelos ou de orelhas, beliscões ou abanões), do pé (e.g., pontapé ou calcadela), da boca (e.g., mordedura), de um objeto atuando como instrumento contundente (e.g., cinto, sapato, colher de pau), cortante (e.g., lâmina de barbear, X-ato ou faca), perfurante (e.g., ponta de tesoura, agulhas) ou através de outras caraterísticas (e.g., cigarro, secador de cabelo ou outros instrumentos aquecidos, ou cordas para prender), podendo ter ainda diferentes contornos, como forçar a permanecer em posições desconfortáveis e dolorosas, queimar com produtos cáusticos ou água a ferver, forçar a ingestão de alimentos, objetos ou substância líquidas impróprias, forçar a aceitação do biberão, obrigar a engolir ou sujeitar ao frio (e.g., imersão em banheira com água fria). 
Ainda que se assumam com finalidade educativa, estes comportamentos encerram gestos que podem provocar danos importantes para a saúde, segurança e normal desenvolvimento físico e psicológico daqueles que a eles estão sujeitos, nomeadamente crianças, pondo em causa os direitos e garantias que a lei confere a cada indivíduo.

Os CF são invariavelmente degradantes (Comité dos Direitos da Criança, 2006) mas, além destes, existem outras modalidades de castigo que são, por vezes, até mais cruéis e degradantes incluindo-se aqui, por exemplo, a punição que menospreza, desvaloriza, humilha, ameaça, assusta ou ridiculariza a criança.

\section{0 CASTIGO FÍSICO AO LONGO DA HISTÓRIA}

\section{Aspetos socioculturais}

O CF constitui uma prática secular integrante da maior parte das culturas e épocas, inclusive no contexto da educação religiosa (Maimon, 1945). Esta prática, traduzida pela violência física, esteve sempre ligada ao papel que na sociedade e na família foi sendo atribuído à criança e que em alguns casos persiste até à atualidade. Este papel, ao invés de conferir à criança um estatuto próprio enquanto pessoa titular de direitos era, antes, potenciador de práticas violentas contra ela perpetrada, pelo que, além de frágil, a criança foi sempre um ser desprotegido (Magalhães, 2010).

Encontram-se relatos da prática de CF no século X a.C. (e.g., Míshle Shlomoh - Provérbios de Salomão), bem como nas civilizações clássicas, sendo usado na Grécia, Roma e Egipto como forma de impor disciplina judicial e educacional (McCole e col, 1999) - bater em crianças era um comportamento normativo e não ilegal. Também no Talmud há indicação de que o pai podia bater nos seus filhos, e um professor nos seus alunos, mas apenas com um determinado modelo de sapato de uso comum na época (em pele) (Epstein, 1935).

No final do século VII a.C., Senaqueribe, um sábio assírio (mencionado na Tobit), escreveu: "O filho que é treinado e ensinado e [cujos] pés em obstáculos colocado [prosperará]" (Baron, 2005). E, ainda, "não retires o teu filho do castigo, senão tu não serás capaz de o salvar [da] maldade. Se eu te ferir, meu filho, tu não queres morrer, mas se eu te deixar entregue a ti próprio e ao teu coração tu [não queres viver] " (Pritchard, 1978). 
Uma voz contraditória surgiu no século VI a.C. com Alexandrino Pseudo-Phocylides, clamando que "não se usa a mão violentamente em crianças (...) não se pode ser severo com os filhos, mas sim gentil." (Collins, 1997) e que "se um pai estiver excessivamente irritado, e por isso punir ou matar um filho, não é, como no direito romano, imune às consequências dos seus atos: deverá ser assassinado" (Cohen, 1946).

No século IV a.C., na Grécia, Menandro afirmou que "quem não é açoitado não é educado" (Cohen, 1946). Também cerca de 2000 a.C., existem referências de que em escolas da Suméria os alunos eram castigados se fossem os primeiros a sair da sala, se falassem sem permissão, se não soubessem falar sumeriano, se não tivessem uma caligrafia cuidada ou quando chegavam atrasados (Kramer, 1961).

Durante a baixa e média Idade Média, sabe-se que não eram reconhecidas às crianças as suas necessidades específicas nem os seus direitos. Imperava, como comportamento normativo, a prática de castigos humilhantes e violentos, a negligência e o abandono afetivo, a exploração pelo trabalho e atos sexuais com adolescentes; tudo isto fazia parte do quotidiano e era naturalmente admitido (Elliman e col, 2000).

No século XVI, Desiderius Erasmus referiu-se à importância da educação em idades precoces, tendo comparado a criança com cera que pode ser moldada enquanto ainda está macia (Cunningham, 2005). John Locke, no século XVII, foi um dos pensadores que maior responsabilidade terá tido na modificação das atitudes relativamente à infância, através da publicação, em 1693, do livro "Algumas Reflexões sobre a Educação", no qual projectou a imagem da criança como tabula rasa, a partir da qual a educação podia fazer uma grande diferença (Cunningham, 2005; Heywood, 2001).

Outro autor de referência obrigatória neste domínio é Jean-Jacques Rousseau (século XVIII) que, pela primeira vez, afirmou que "a criança tem o direito a ser criança e a ser feliz nessa condição, antes de se tornar um adulto", reiterando o facto de a criança nascer inocente e de correr o risco de ser sufocada por preconceitos ou autoridade, defendendo claramente também o fim dos castigos físicos aplicados a crianças (Canha, 2003).

Até meados do século XIX são raros os relatos sobre $\mathrm{CF}$, não porque esse gesto não existisse mas porque era considerado normal (Weissbach, 1977). Encontram-se, ainda assim, em alguns textos, referências sobre a utilização do CF enquanto auxiliar educativo como, por exemplo, nas escolas britânicas; a partir de 1860, na Grã-Bretanha, a lei passou a autorizar o castigo corporal da criança "para corrigir o que está mal ", podendo os pais "causar razoável a moderada punição corporal" (Gibson, 1978; Elliman e col, 2000).

No final do século XIX alguns países começaram a considerar como ilegal o CF nas escolas; Portugal é um exemplo desses países, existindo uma Portaria 
publicada em 1893 que proíbe o CF na escola, apesar de ainda consentir a aplicação de castigos que "não ofendessem a saúde do aluno". Nos EUA, em 1867, em mais de 27 Estados, era proibido o CF nas escolas e, no entanto, em 1977, o Supremo Tribunal daquele país rejeitou a moção de que a punição corporal de crianças era cruel (Wilgoren, 2001).

A noção de que as crianças possuem direitos individuais foi articulada pela primeira vez em 1923, na Declaração sobre os Direitos da Criança, publicada pela Aliança Internacional Save the Children (Save the Children, 2010). Um ano depois, esta declaração foi adotada pela Liga das Nações e tornou-se conhecida como a Declaração de Genebra dos Direitos da Criança. Nessa sequência, nos anos 30 novas ideias sobre a criança e a infância começaram a ganhar espaço em muitos países enquanto aumentava o conhecimento entre pediatras, psicólogos infantis e pedagogos sobre o impacto negativo do CF e do tratamento emocionalmente abusivo sobre as crianças.

A Suécia foi o primeiro país a abolir o CF. Em 1979, a "Emenda ao Código de Pais e Filhos" regista a "proibição de todas as formas de castigo físico e outro tratamento emocionalmente abusivo", tendo passado por um longo processo prévio de sensibilização social e cultural através de uma campanha publicitária, dirigida aos pais, que teve a duração de várias décadas. Essa inédita campanha, que surgiu na década de 1930 após um jornal sueco ter publicado uma série de artigos destacando o drama das crianças que estavam sob os cuidados de instituições devido a "comportamento antissocial" ou por terem sido negligenciadas, desenvolveu-se através de reuniões, palestras e apresentações de organizações não-governamentais, associações educativas que envolviam pais e outros responsáveis de todo o país em discussões sobre como criar os filhos sem violência. Esta iniciativa gerou uma consciência de que as crianças que são assustadas, ameaçadas e agredidas ficam com marcas por toda a vida, aprendendo não a corrigir comportamentos, mas sim que violência gera violência, ressaltando desta campanha que "as crianças devem ser tratadas com respeito e compreensão no sentido de que cresçam como cidadãos responsáveis".

A partir do exemplo da Suécia, e com o apoio da Convenção das Nações Unidas sobre os Direitos da Criança, outros países no mundo passaram a adotar estratégias sociais e legais no sentido de abolir o CF de crianças. Esta Convenção (Convenção dos Direitos da Criança, 2004) determina claramente que os governos devem tomar medidas legislativas e outros procedimentos para proteger a criança de todas as formas de violência física e mental quando esta estiver sob o cuidado dos pais, representantes legais ou qualquer outra pessoa por ela responsável.

A Assembleia Parlamentar do Conselho da Europa apelou formalmente, em 2004, à erradicação do CF em todo o continente europeu - "qualquer castigo 
físico contra crianças é uma quebra dos seus direitos fundamentais à dignidade humana e à integridade física" (Convenção dos Direitos da Criança, 2004).

\section{A evolução científica}

Estes gestos, perpetrados ao longo da História, apenas começaram a ser objeto de interesse por parte dos cientistas a partir da primeira década do século XX, talvez por falta de uniformidade de opiniões, considerando-se o CF como aceitável e da responsabilidade dos progenitores (especificamente os do sexo masculino), os quais detinham o direito, e até dever, de punir fisicamente as crianças nas situações de "transgressão".

Em 1920, a psicologia promoveu a área de estudo do desenvolvimento infantil, descrevendo diferentes estadios de desenvolvimento associados ao benefício de diferentes formas de disciplinar. Em 1940, psicólogos e psiquiatras registaram em múltiplas publicações conselhos sobre formas de educar as crianças, questionando o CF mas não o fazendo de forma sistemática. Na década de 40-50, as teorias psicanalíticas de Freud (já afloradas nos anos 1910 e 1920), foram retomadas, considerando-se que o CF no contexto educacional podia provocar dano psíquico a longo prazo, passando a ser abordada a motivação dos progenitores para a aplicação de castigos corporais nas crianças, tendo sido identificados os riscos relacionados com a utilização do CF. Foram estabelecidos os padrões de comportamento para os diversos estadios de desenvolvimento da criança, sendo sugerido e considerado que muitas das "alterações de comportamento" que tinham justificado o CF como método educativo num passado recente, correspondiam a comportamentos normais do desenvolvimento infantil.

Pediatras e psicólogos do desenvolvimento começaram então a examinar de perto a importância do relacionamento pais/filhos, assim como as forças que o promoviam ou enfraqueciam. Nessa sequência surgiu o debate efetivo sobre a distinção entre CF e abuso da criança e, também, sobre o impacto futuro destes comportamentos traumáticos sobre a mesma. Estudos relacionados com sequelas resultantes da utilização regular de CF educativo revelaram os efeitos nefastos sobre o desenvolvimento afetivo, social e cognitivo da criança, com graves repercussões na vida adulta (Weber LND, Dobrianskyj N e col, 2004; Weber LND, Viezzer AP e col, 2004). Desta forma, o CF começou a deixar de ser visto como uma resposta normativa à "maldade" da criança, para passar a ser interpretado como uma resposta desviante do adulto a comportamentos infantis normais.

A partir de 1946 a pediatria assumiu, nos EUA, a liderança na área do aconselhamento sobre disciplina no contexto do desenvolvimento infantil. Em 
1962, com a definição de Kempe sobre "Síndrome da criança batida" (Kempe e col, 1962), surgiu a preocupação sobre a pequena "distância" entre CF e abuso, aparecendo as primeiras guidelines para orientação diagnóstica: “ $O$ castigo físico que causa equimoses ou outro tipo de lesão que exija tratamento médico considera-se como estando fora do campo do castigo aceitável. A presença de equimoses implica traumatismo intenso" e, ainda, "para minimizar o risco de abuso físico é necessário minimizar o uso de castigo físico educativo", reforçando-se, assim, a natureza contínua deste constructo de violência, ou seja, o continuum entre o CF e o comportamento abusivo.

Entretanto verificaram-se alguns retrocessos nesta nova perspetiva sobre o CF. Benjamin Spock publicou, em 1968, "Baby and Child Care" (já com 179 edições), advogando que o CF poderia ser útil em determinadas circunstâncias - “ (...) não sou a favor do castigo físico mas penso que por vezes ele se torna menos venenoso do que outro castigo, porque clarifica a atmosfera entre progenitor e filho (...)" (Smith, 1977). Baumrind, em 1973, sugeriu que os efeitos do CF na criança devem ser considerados tendo em conta o contexto social vigente de "controlo parental", estando este diretamente relacionado com o nível de aceitação de violência física que existe na sociedade, tal como acontece na atualidade (Baumerind, 1973). Em 1977, na obra "Introduction to Clinical Pediatrics" voltou-se a defender o CF como método de condicionamento em certos estadios de desenvolvimento infantil (Smith, 1977).

Outras posições mais moderadas surgiram também. Em 1994, Graziano definiu o conceito de "violência sub-abusiva" contra crianças, sendo este termo usado para descrever aquele tipo de violência socialmente aceitável dirigida a crianças com a finalidade de disciplinar, desferindo estalos, palmadas ou provocando traumatismos usando objetos (Graziano, 1994). Simmons e colaboradores (Ronald e col, 1994) referiram-se à situação de "parentalidade insuportável”, relacionando-a com a convivência com gritos, palmadas, empurrões e traumatismo com objetos, misturando-se assim com a definição de abuso e saindo reforçada a ideia da necessidade de focar a atenção na natureza contínua, e não dicotómica, destes constructos (Whipple, 1997).

Mais recentemente, enquanto alguns pediatras norte americanos se opunham terminantemente ao uso de qualquer tipo de $\mathrm{CF}$, outros consideravam existir situações em que o CF “não abusivo” devia continuar a ser uma opção de disciplina (McCormick, 1992). Gershoff, autor de uma das maiores revisões bibliográficas realizada sobre este tema, manifestou a sua total oposição a qualquer tipo de CF (Gershoff, 2002, 2008), enquanto outras três revisões bibliográficas levavam a conclusões menos absolutas (Larzele, 1996, 2005).

Mas, mesmo com intenção disciplinar educativa, o ato de bater facilmente ultrapassa os limites à partida admitidos pelo próprio educador. Segundo Bessa e colaboradores, a punição física muitas vezes é utilizada de maneira 
descontrolada, mais como alívio para quem bate do que como meio disciplinar (Bessa e col, 1989). Quando o CF não conduz aos resultados desejados pelo educador, a tendência é o aumento da intensidade e da frequência levando a um círculo vicioso que pode terminar em situações trágicas. Zagury postula que em algumas situações, mesmo apanhando e com medo e identificando esse ato como humilhante, a criança encontra forças para enfrentar os pais quando diz "nem doeu!"; essa é uma forma de defesa que pode redundar em mais agressões, devido a um possível descontrolo por parte dos progenitores/ cuidadores (Zagury,1993).

Alguns autores identificaram nos seus estudos as dimensões que mais comummente se encontram associadas às definições de CF (Strauss e col, 1991): (a) tipo de comportamentos dos progenitores/cuidadores; (b) níveis de severidade de punição; (c) intenção do progenitor/cuidador; e (d) antecipação de efeitos na criança. Identificaram, ainda, que estas dimensões podem ser agravadas por (Strauss e col, 1994): (a) fontes e nível de stresse na família associados ao temperamento da criança; (b) antecedentes dos progenitores/ cuidadores e caraterísticas das suas personalidades; c) valores culturais e religiosos; e (c) normas sociais. Associados às situações anteriores estão referenciados fatores de stresse específicos associados a famílias em maior risco para ocorrência de CF (Wolfner e col, 1993): (a) maternidade precoce; (b) alta mobilidade geográfica; (c) família numerosa; (d) pobreza; (e) situação étnica minoritária; (f) baixo nível educacional; e (g) desemprego. Neste modelo de abordagem também Barroso (2010) discute que o processo de aplicação de práticas fisicamente punitivas na relação pais/filhos se encontra, de alguma forma, compreendido no exercício da parentalidade e que este decorre de um conjunto de circunstâncias sociais e/ou dificuldades interpessoais - individuais, familiares, sociais e culturais - no desempenho das necessárias tarefas da parentalidade.

Várias definições de CF têm sido propostas:

a) Ato de violência legalmente permissível adotado no contexto de papel parental incluindo a forma de violência severa como por exemplo agressão utilizando objetos (Strauss, 1991);

b) Forma de maus-tratos em que uma lesão é infligida à criança por um cuidador através de diversos meios e de forma não acidental, de maneira a provocar-lhe dor ou mau estar físico, incluindo bater com a mão, com um pau, correia ou outros objetos, socos, pontapés, abanões, empurrões, queimaduras, etc. - Third National Incidence Study (NIS-3), 1996 (Sedlak e col, 1996); 
c) Lesões que, dependendo da sua gravidade, impliquem a necessidade de cuidados médicos, as quais podem ir desde o eritema que desaparece em algumas horas até lesões graves que terminam na morte, resultantes de traumatismos provocados pelos cuidadores - tem por base critérios médicos e coloca a tónica sobre o efeito que a lesão tem na criança e menos na intenção que se depreende existir por parte do cuidador (Kempe A, 1998);

d)Todas as formas de violência física ou mental, abuso ou tratamento negligente, maus-tratos ou exploração, inclusive abuso sexual assim como o uso intencional da força ou poder físico, em forma de ameaça ou efetivamente, contra uma criança, por um indivíduo ou grupo, que prejudique ou que tenha grandes probabilidades de prejudicar a saúde, sobrevivência, desenvolvimento ou dignidade da criança (Krug e col, 2002);

e) Qualquer ação utilizando força física com a intenção de provocar algum grau de dor ou desconforto ainda que leve (Convenção dos Direitos da Criança, 2004);

f) Qualquer punição em que a força física seja usada com a intenção de causar um certo grau de dor ou desconforto, ainda que ligeiro (Comité dos Direitos da Criança, 2006);

g) Ação de natureza disciplinar ou punitiva através do uso da força física que resulte em sofrimento ou lesão à criança ou adolescente (projeto de Lei $n^{\circ}$ 7672/2010 que altera a Lei $n^{\circ}$ 8069, de 13 de julho de 1990, e que dispõe sobre o Estatuto da Criança e do Adolescente, apresentado ao Senado brasileiro em 14 de dezembro de 2011); este projeto de Lei define ainda tratamento cruel ou degradante como "conduta ou forma cruel de tratamento que humilhe, ameace gravemente ou ridicularize a criança ou o adolescente", considerando-o, tal como no caso do CF, se causados por "pais, integrantes da família ampliada, responsáveis, agentes públicos executores de medidas socioeducativas ou qualquer pessoa encarregada de cuidar, tratar, educar ou proteger crianças e adolescentes".

Os limites de intensidade, frequência e formas do CF educativo tolerados e culturalmente aceites, continuam, contudo, muito distintos entre grupos sociais e familiares.

É fundamental perceber que os fatores associados à violência dirigida às crianças estão usualmente associados a uma rotura na relação familiar a qual atenta contra a dignidade e o bem-estar dessa criança e, por vezes, contra a sua própria vida. Este é o principal motivo pelo qual a prevenção da violência 
doméstica e dos maus tratos é hoje reconhecida como uma preocupação dos direitos humanos, incluindo-se aqui o $\mathrm{CF}$.

\section{0 CASTIGO FÍ́ICO NO SÉCULO XXI}

No final do século XX o CF continuava a ser perpetrado por cerca de 94\% dos progenitores em todo o mundo (Strauss, 1999). De facto, a nível mundial, apenas uma muito ínfima percentagem de crianças está na atualidade legalmente protegida relativamente ao $\mathrm{CF}$, quer na família, quer nas instituições, designadamente nas escolas e lares.

Contudo, um número significativo de países (StopHitting, 2008) (29 países até ao ano de 2011) baniu já o seu uso (Tabela 1), promulgando leis que proíbem o CF em crianças, em contextos familiar e educacional, por estes serem considerados como uma violação dos direitos humanos.

Tabela 1 - Países e ano de abolição do CF em crianças (espaço escola e família)

\begin{tabular}{ll}
\hline Ano & País \\
\hline 1979 & Suécia \\
1983 & Finlândia \\
1987 & Noruega \\
1989 & Áustria \\
1994 & Chipre \\
1997 & Dinamarca \\
1998 & Letónia \\
1999 & Croácia \\
2000 & Alemanha; Bulgária; Israel \\
2003 & Islândia \\
2004 & Hungria; Ucrânia; Roménia \\
2007 & Espanha; Grécia; Holanda; Nova Zelândia; Portugal; Uruguai; Venezuela \\
2008 & Costa Rica; Luxemburgo; Liechtenstein \\
2009 & Moldávia \\
2010 & Quénia; Tunísia; Polónia \\
\hline
\end{tabular}

Na Suécia, o CF por progenitores foi legalmente banido em 1979, sendo este gesto considerado como medida social e política necessária para reduzir a questão do abuso de crianças. Num estudo realizado em 1999, naquele país, os números encontrados revelaram que a proibição do CF pouco adiantou (Larzele, 1989), havendo evidências, não publicadas, que sugerem que a frequência de abuso da criança continuou a manter-se elevada, apesar da taxa de mortalidade associada ter diminuído. 
Em Inglaterra a "bengalada" foi abolida das escolas públicas só em 1986 (Education Act), continuando a ser aceite e tolerado o CF na família e nas escolas privadas, desde que os progenitores concordem com o código disciplinar da escola (Elliman e col, 2000).

A Lei Canadiana proíbe o CF mas o Supremo Tribunal Canadiano, em janeiro de 2004, passou a permitir aos progenitores a possibilidade de dar palmadas nas crianças, mas, apenas, naquelas com idades compreendidas entre os 2 e os 12 anos, desde que com limitação na força usada na palmada (Durrant, 2003).

Em Portugal, o CF está proibido nas escolas, a nível institucional em geral e no espaço da família, constituindo um crime público (integrado nos crimes de "Violência doméstica" e de "Maus tratos"), existindo contudo, ainda no século XXI, acórdãos que ainda consideram que "o facto de o arguido, com intuito de punir e molestar o filho menor com quem vive, ter desferido, na residência e na sequência deste ter pegado sem o seu consentimento na quantia de $20 €$, the ter desferido no rabo com um cinto duas pancadas, que the causaram dores e ferimentos sem necessidade de tratamento hospitalar não revela uma imagem global do facto agravada nem concretiza um especial conteúdo de culpa em resultado de formas de realização do facto especialmente desvaliosas ou de qualidades da personalidade do agente especialmente desvaliosas (sobre os conceitos de especial censurabilidade e perversidade)", considerando-se ainda no mesmo acórdão que "o enquadramento da atuação do arguido nos atos disciplinadores exercidos no âmbito dos poderes/deveres de correção atribuídos aos pais, não autorizam a qualificação jurídica agravada sugerida na acusação, pelo que os factos alegados integram a autoria material por parte do arguido de um crime de ofensa à integridade física mas simples, p. e p. pelo artigo 143, $n^{\circ} 1$, do Código Penal" (STJ, janeiro de 2010).

$\mathrm{O}$ país que mais recentemente prepara a penalização criminal do $\mathrm{CF}$ de crianças, é o Brasil, tendo sido apresentado ao Senado, em dezembro de 2011, para promulgação, um projeto de Lei (projeto de Lei 7672/2010 artigo $18^{\circ}$ ), já designado de "Lei da Palmada". A publicação desta Lei será o culminar de um processo com cerca de 20 anos de evolução, iniciado em 1990, considerando-se que a criança e o adolescente têm o direito de serem educados e cuidados sem o uso de CF ou de tratamento cruel ou degradante, como formas de correção, disciplina, educação ou qualquer outro pretexto, pelos pais, pelos integrantes da família ampliada, pelos responsáveis, pelos agentes públicos executores de medidas socioeducativas ou por qualquer pessoa encarregada de cuidar, tratar, educar ou proteger.

Mas, apesar de existirem muitas diferenças em termos culturais e sociais sobre a legitimidade e a eficácia do $\mathrm{CF}$, as pessoas em geral continuam a legitimá-lo. Enquanto num estudo Canadiano, 59\% das pessoas inquiridas 
entenderam que o CF era altamente desaconselhado (Durrant, 2003), estudos efetuados nos EUA identificaram que $84 \%$ dos inquiridos concordaram que "por vezes é necessário disciplinar uma criança com um bom estalo" (Strauss, 1996; Durrant, 2003). Na Nova Zelândia, um estudo onde foram inquiridos indivíduos com 25 anos de idade com filhos (aplicando a Parent-Child Conflict Tactics Scale), identificou que 75\% daqueles reportaram ter sido fisicamente castigados enquanto crianças e quase $12 \%$ dos mesmos referiram ter castigado fisicamente, de forma severa, um filho durante o ano anterior ao do estudo (Woodward e col, 2007). Outro estudo na República da Coreia revelou que 90\% dos progenitores entendiam o CF como necessário (Kim, 2000) e num inquérito efetuado a crianças, proveniente do Yemen, cerca de $90 \%$ dos inquiridos descreveram que o CF e a humilhação eram as principais formas de disciplina na família, sendo a mais comum a agressão física (Harper, 2005).

\section{COMENTÁRIO FINAL}

Para muitos torna-se hoje incompreensível porque é que as crianças recebem menos proteção contra ataques à sua dignidade e integridade psíquico-física do que os adultos, sendo, em razão do seu estado de desenvolvimento e até por vezes da sua compleição física, particularmente vulneráveis a danos físicos e psicológicos. Mas, como se viu, nem todos partilham desta opinião; muitas crianças ainda vão necessitar de esperar mais tempo para receber a mesma proteção legal que os adultos usufruem contra agressões deliberadas - como é o caso do CF.

Neste estudo de revisão percebemos, através da abordagem dos aspetos socioculturais e da evolução científica sobre este tema, que a eliminação do $\mathrm{CF}$ de crianças requer mais do que mudanças legislativas, estando-lhe fortemente associados fatores cognitivos e culturais, relacionados com crenças partilhadas por cuidadores, crianças e até profissionais.

De facto, apesar das leis, convenções e tratados, estes comportamentos continuam a ser socialmente tolerados. Tal facto resulta de circunstâncias socioculturais (sobretudo a tradição e a transmissão geracional desses comportamentos), o que legitima e incentiva os castigos à luz daquilo que é ainda considerado como sendo o "poder de correção" ou o "poder-dever de educar". Este poder continua, assim, a confundir-se com o poder de agredir, de abusar, mesmo que se trate "apenas" de um beliscão, de uma palmada, bofetada ou puxão de orelhas. Além do dano psicológico, tais práticas podem provocar danos físicos significativos e, em alguns casos, mesmo fatais (Magalhães, 2010).

O uso de conceitos como "castigo moderado" e "castigo tolerado" (AAP, 2001) resulta da circunstância de persistir ainda a ideia de que a criança é 
propriedade dos pais e de que os pais têm direitos, mascarados de "deveres", sobre aquelas. Estes "direitos" baseiam-se na relação de poder/confiança entre progenitores/crianças/progenitores, no poder do mais forte sobre o mais fraco, e são perpetuados através da violência e da humilhação.

Estes castigos, que constituem uma violência, podem ser um ato deliberado de castigo ou apenas a reação impulsiva de um cuidador que perdeu o controlo da situação. Ambas as causas constituem uma quebra dos direitos humanos, sendo o respeito pela dignidade humana e o direito à integridade física princípios universais. A OMS, a UNICEF e muitas outras organizações internacionais consideram hoje que o castigo físico deve ser entendido como uma forma de abuso.

O objetivo da proibição do CF contra crianças é a prevenção do abuso associado a danos graves, muitas vezes irreversíveis e até fatais, promovendo-se a mudança de atitude e das práticas no sentido da implementação de métodos não violentos de educação, importando neste ponto citar Cordeiro (2011), pediatra português que propõe métodos de disciplina adaptados a casos concretos e a faixas etárias, sem recurso à violência. Neste sentido, é fundamental construir uma mensagem clara sobre o que é considerado como comportamento absolutamente inaceitável, apesar de ter como finalidade a educação; ou seja, ainda que se trate de uma tarefa altamente complexa, é necessário estabelecer qual é o limite entre o castigo legítimo e positivo (não-violento) e a violência física e psicológica (abuso). Efetivamente, por vezes os adultos responsáveis por crianças revelam-se confusos quanto à forma eficaz de lidar com situações/comportamentos difíceis exibidos por aquelas.

Este é um assunto pelo qual todos somos responsáveis, mas muito particularmente aqueles que trabalham com crianças. Lembremo-nos que no seu dia-a-dia muitas crianças continuam a ser espancadas, a levar estalos, murros, abanões, beliscões, pontapés, tareias com paus, chicotes ou cinto em nome da "disciplina" e da "educação", em geral pelas mãos de adultos dos quais dependem e em quem confiam - "existem muitas coisas terriveis no mundo, mas a pior delas é quando uma criança tem medo de seu pai, de sua mãe ou de seus professores" (Janusz Korczak, pediatra, escritor e pedagogo infantil polaco, 1878-1942) (Beiner F, 1987).

\section{REFERÊNCIAS BIBLIOGRÁFICAS}

AAP (American Academy of Pediatrics) Division of Child Health Research. AAP survey on corporal punishment reveals divergent views".AP News 1998; 14 (9): pp. 16 [documento online] 2001 [atualizado em 2011 Dez 08]. Disponível em: at: http://www.aap.org/. 
Baron JH (2005). Corporal Punishment of Children in England and the United States: Current Issues. The Mount Sinai Journal of Medicine; No. 1 January.

Barroso RG (2010). Da punição física ao abuso físico: conceptualização e consequências práticas. Revista Portuguesa de Ciência Criminal; 20(2): 279-304.

Baumerind D (1973). The development of instrumental competence through socialization. In A.D. Pick (Ed.), Minnesota Symposia on child psychology (Vol. 7). Minneapolis, MN: University of Minnesota Press; p. 3-46.

Beiner F, Dauzenroth E, Lax E (1987). J. Korczak, bibliographie, Quellen und Çiteratur 1943-1987. Heinsberrg, Agentur Dieck (eds).

Bessa MRV, Oliveira CA, Ricas J, Campos MGA, Castro MHMD (1989). Abordagem psicológica da criança. In: Leão E, Mota JAC, Viana MB, Correa EJ, organizadores. Pediatria ambulatorial. $2^{a}$. ed. Belo Horizonte: Cooperativa Editora e de Cultura Médica. p.115-24.

Bourdieu P (1996). A ilusão biográfica. In: Ferreira, Marieta de Morais e Amado, Janaína (org). Usos e abusos da história oral. Rio de Janeiro: Editora da Fundação Getúlio Vargas. $484 \mathrm{p}$.

Canha J (2003). Criança Maltratada. O papel de uma pessoa de referência na sua recuperação. Estudo prospectivo de 5 anos ( $2^{\mathrm{a}}$ ed.). Coimbra: Quarteto Editora.

Cohen A (1946). Proverbs. London: Soncino Press. p.148.

Collins JJ (1997). Jewish wisdom in the Hellenistic age. Edinburgh: Westminster John Knox Press. p.167.

Cordeiro M (2011). O grande livro dos medos e das birras. Lisboa: A Esfera dos Livros.

Comité dos Direitos da Criança (2006). General Comment No.8. The Right of the Child to Protection from Corporal Punishment and Other Cruel or Degrading Forms of Punishment. (Art. 19, 28 (2) and 37, inter alia), CRC/C/GC/8.

Convenção dos Direitos da Criança [documento online] 2004 [documento online] [atualizado em

Cunningham H (2005). Children and Childhood in Western Society Since 1500 (2 ed.). Harlow, England: Pearson Education Limited. Dez 08]. Disponível em: http://www. stophitting.com/.

Durkheim E (1984). Sociologia, Educação e Moral. Porto. Rès-Editora. 398 p.

Durrant JE (2003). Maternal Beliefs about physical punishment in Sweden and Canada. Journal of Comparative Family Studies; 34: 586-604. Citado em Corporal Punishment: Prevalence, Predictors and Implications for Child Behavior and Development (2005). In: Hart SN. Eliminating Corporal Punishment. Paris, UNESCO.

effects on children. [document online] 2008 [atualizado em 2011 Dez 08]. Columbus, OH: Center for Effective Discipline.Disponível em: http://www.phoenixchildrens.com/ PDFs/principles_and_practices_of_effective_discipline.pdf.

Elliman D, Lynch MA (2000). The physical punishment of children. Arch Dis Child 2000; 83(3): 196-98.

Epstein I (1935). The Babylonian Talmud: Baba Bathra. London: Soncino Press;. 21a. p.106.

Gershoff ET (2002). Corporal punishment by parents and associated child behaviors and experiences: A meta-analytic and theoretical review. Psychological Bulletin; 128: 539-579.

Gershoff ET. Report on physical punishment in the United States: what research tells us about its 
Gibson I (1978).The English vice. London Duckworth Press; 1978. p.48-51.

Graziano A (1994). Why we should study sub abusive violence against children. Journal of Interpersonal Violence. 9: 412-463.

Harper K, Horno P, Landsdown G et al. Physical and Humiliating Punishment of Children in Yemen. Save the Children Sweden. International Alliance Save the Children. Ending Physical and Humiliating Punishment of Children. Making It happen, part. 2 [document on line] 2005 [atualizado 2011Dez08]. Disponívelem:http://mena.savethechildren.se/ Global/scs/MENA/Resources/Ending\%20Physical\%20and\%20Humiliating\%20Punishment $\% 20$ of $\% 20$ Children $\% 20 \% 28$ ENGLISH $\% 29$.

Heywood C (2001). Uma História da Infância: Da Idade Média à Época Contemporânea no Ocidente. Porto Alegre: Artmed Editora

Kemp A (1998). Abuse in the family: An introduction. Pacific Grove, CA: Brooks/Cole Publishing Co.

Kempe CH, Silverman FN, Steele BF, Droegemueller W, Silver HK (1962). The battered-child syndrome. JAM 1962; 181:17-403.

Kim D-H (2000). Children's Experience of Violence in China and Korea: A Transcultural Study. Child Abuse \& Neglect; 18: 155-166.

Kramer SN (1961). The Sumerians: their history, culture, and character. Chicago: University Press. p. 235-236.

Krug EG, Dahlberg LL, Mercy JA, Zwi AB, Lozano R (2002). Relatório Mundial sobre a Violência e

Larzele RE (1996). A review of the outcomes of parental use of non abusive or customary physical punishment. Pediatrics 1996; 98: 824-828.

Larzele RE (2005). Child outcomes of nonabusive and customary physical punishment by parents: An updated literature review. Clinical Child and family Psychology Review; 8: 1-37.

Larzelere RE, Johnson B (1989). Evaluations of the effects of Sweden'sspanking ban on physical child abuse rates: a literature review. Psychol Rep; 85(2): 381-92.

Magalhães T (2010). Violência e Abuso. Respostas simples para questões complexas. Imprensa da Universidade de Coimbra. p 61-96.

Maimon S (1945). Autobiography. London: East and West Library. p. 31.

McCole W, Robert A (1999). Study of Attitudes Towards Corporal Punishment as an Educational Procedure the Earliest Times to the Present, Nifmegen University; $1^{\text {st }}$ ed. Chap. 2.3 to 2.6 .

McCormick KF (1992). Attitudes of primary care physicians toward corporal punishment. Journal of the American Medical Association. 267: 3161-3165.

Pritchard JB (1978). Ancient Near Eastern texts relating to the Old Testament. Princeton: University Press. p. 428b.

Projeto Lei 7672/2010. [document on line] 2011 [atualizado 2011Dez18]. http://www.camara. gov.br/proposicoesWeb/fichadetramitacao?idProposicao=483933.

Ronald LS, Johnson C, Conger RD (1994). Harsh Corporal Punishment versus Quality of parental Involvement as an explanation of Adolescent Maladjustment. Journal of marriage and The Family. 56: 591-607. 
Save the children. [document on line] 2010 [atualizado 2011 Dez 08]. Disponível em: http:// www.savethechildren.net/alliance/about_us/mission_vision/index.html.

Sedlak AJ, Broadhurst DD. Third National Incidence Study of Child Abuse and Neglect (NIS-3 Final Report). US Dept of Health and Human Services. Contract No. 105-941840. [document on line] 1996 [atualizado 2011 Dez 08]. Disponível em: http://www. childwelfare.gov/pubs/statsinfo/nis3.cfm.

Smith DW (1977). Introduction to clinical pediatrics. Philadelphia: Saunders. 452 p. (Pediatrics series. xviii). p. 1926-81.

StopHitting. Discipline and the Law: Legal Reforms. [document online] 2008 Dez [atualizado 2011

Straus MA, Moynihan MM (1994). Who spanks the most? In M. A. Straus (Ed.), Beating the devil out of them: Corporal punishment in American families (pp. 49-63). New York: Lexington Books.

Strauss MA, Gelles RJ (1991). Physical violence in American families: Risk factors and adaptations to violence in 8.145 families. Incidence Rates, Causes, and Trends. Abused and Battered: Social and Legal Responses to Family Violence, ed. by D. D. Knudsen and J. L. Miller. NY: Aldine De Gruyter.

Strauss MA, Mathur AK (1996). Social Change and Trends in Approval of Corporal Punishment by Parents from 1968 to 1994. In: Frehsee D et al. (Eds). Violence against Children. Berlin and New York, Walter de Gruyter, p.91-105.

Strauss MA, Stewart JH (1999). Corporal punishment by American parents: National data on prevalence, chronicity, severity, and duration, in relation to child and family characteristics. Clinical Child and Family Psychology Review; 2: 55-70.

Weber LND, Dobrianskyj N, Prado PM, Viezzer AP, Bradenburg OJ (2004). Identificação de estilos parentais: o ponto de vista dos pais e dos filhos. Psicol Refl ex Crit;17(3): 323-31.

Weber LND, Viezzer AP, Bradenburg OJ (2004). O uso de palmadas e surras como prática educativa. Estud Psicol (Natal). 9(2): p. 227-37.

Weissbach LS (1977). "Child Labor Legislation in Nineteenth-Century France". The Journal of Economic History 37 (1): 268-271.DOI:10.1017/S0022050700112112

Whipple EE, Richey CA (1997). Crossing the line from Physical Discipline to Child Abuse: How much is too much? Child Abuse \& Neglect. 21(5): 431-444.

WHO \& ISPACN (2006). Preventing Child Maltreatment: a guide to taking action and generating evidence. [document on line] 2006 [atualizado 2011Dez08]. http://whqlibdoc. who.int/publications/2006/9241594365_eng.pdf.

Wilgoren J. Lawsuits touch off debate over paddling in the schools. N Y Times, Sect. A:1, 22

Wolfner GD, Gelles RJ (1993). A profile of violence toward children: A national study. Child Abuse \& Neglect, 17, 197-212.

Woodward LJ, Fergusson DM, Chesney A, Horwood LJ (2007). Punitive parenting practices of contemporary young parents. N Z Med J.14 (120): 1267-2866.

Zagury T (1993). Palmada - sim ou não? Educar sem culpa. São Paulo: Círculo do Livro; p.111-20. 
Resumo: 0 castigo físico de crianças. Estudo de revisão

0 presente trabalho tem como objetivo fazer uma reflexão sobre o castigo físico (CF) como forma de disciplina aplicada a crianças e jovens em contexto educacional no espaço da família.

É feita revisão bibliográfica sobre a representação social e legal do CF ao longo dos tempos em várias sociedades, incluindo a forma como a ciência e as religiões olharam para o mesmo tema, e como ainda, na actualidade, continuam a fazê-lo. Um castigo tem usualmente como objectivo promover a correcção, punir ou reprimir uma conduta que se considera incorrecta. Pode acontecer no âmbito de um sistema legal ou a nível institucional ou familiar. Nestes dois últimos contextos, tendo em conta o tipo de relacionamento interpessoal "cuidador versus menor de idade", facilmente se pode transformar em comportamentos física e psicologicamente violentos ou até de coacção que se sabe deixarem para o futuro um conjunto de sequelas a nível emocional e até, eventualmente, a nível físico, além do risco de reprodução transgeracional, conforme é corroborado por vários estudos científicos citados. Apresenta-se uma reflexão sobre a actualidade social e legal do CF na sociedade actual em vários países. Mesmo com intenção de educar, os gestos de natureza violenta põem em causa os direitos das vítimas. 0 entendimento do CF não está relacionado com a descrição do gesto aplicado, mas com a gravidade da lesão resultante. As definições médicas concentram-se mais sobre o efeito que a lesão tem sobre a criança do que sobre a intenção demonstrada por parte do cuidador. A OMS, assim como a UNICEF, consideram que "o castigo físico deve ser entendido como uma forma de abuso".

Palavras-chave: Castigo físico; educação; abuso; violência; crianças e jovens; contexto cultural e social.

\section{Summary: Physical punishment against children. A review}

The aim of this study is to discuss physical punishment (PP) as a mean of discipline applied to children and teenagers in an educational context in a family environment.

A bibliographic research is made on social and legal representation of PP in various societies throughout time including the perspective of science and religion on this topic, focusing the current outlook on this subject. Punishment is usually used as a means of correction, to punish or reprimand certain behavior which is considered incorrect. This can happen in a scope of a legal system or at institutional or family level. In the last two contexts, taking into account the type of interpersonal relationship "caregiver versus minor", it could be easily transformed into violent physical and psychological behavior or even coercion which is known to leave a number of after-effects at emotional level or even, eventually, at a physical level, surely existing the risk of generational reproduction, as is corroborated by various quoted scientific studies. A research of bibliography about current social and legal point a view over PP in present society in various countries is presented.

Even with the purpose of education, the gestures of offensive nature may put victim's rights at stake. The understanding of PP is not so closely tied to the type of the gesture applied, but more with the seriousness of the resulting injury. The medical definitions 
concentrate nowadays more on the effect which the injury has on the child than on the intention demonstrated by the caregiver. The OMS as well as UNICEF consider that "physical punishment must be understood as a form of abuse."

Key-words: Physical punishment; education; abuse; violence; children and teenagers; cultural and social context.

Résumé: Les châtiments corporels sur les enfants. Étude de révision

Ce travail vise à réfléchir sur les châtiments corporels (CC) comme une forme de discipline appliquée aux enfants et aux adolescents dans le contexte éducatif et au sein de la famille. Les auteurs on fait une revue de la littérature sur la représentation sociale et juridique du CC au cours des années dans de nombreuses sociétés, notamment la façon dont la science et la religion ont regardé le même thème, et encore, comme aujourd'hui, continuent à le faire. Une punition est habituellement conçu pour promouvoir la correction, de punir ou sanctionner une conduite qui est jugée incorrecte. Il peut arriver dans un système juridique ou institutionnel ou familial. Dans les deux derniers contextes, en tenant compte du type de relation interpersonnelle «soignant contre un mineur», la punition peut facilement se transformer en comportement psychologiquement et physiquement violent et coercitif et même laisser, à l'avenir, un ensemble de conséquences émotionnelles et, éventuellement, même physiques. Il doit également être envisagé le risque de reproduction transgénérationnelle laquelle est corroboré par plusieurs études scientifiques citées. Ont présente une réflexion sur le cadre social et juridique actuel du CC dans la société d'aujourd'hui dans de nombreux pays.

Même avec l'intention d'éduquer, les gestes de nature violente saper les droits des victimes. La compréhension de ce que est le CC n'est pas liée à la description du geste appliqué, mais avec la gravité du dommage subi. Le focus des définitions médicales se concentre davantage sur l'effet de la lésion sur l'enfant victime que sur l'intention démontrée par le soignant. L'OMS et l'UNICEF considèrent que «le châtiment physique doit être compris comme une forme d'abus».

Mots-clés: Punition corporel; éducation; abus physique; violence; enfants et jeunes; contexte culturel et social.

\section{Pedido de separatas:}

CRISTINA SILVEIRA RIBEIRO

mcribeiro@dpinml.mj.pt 